\title{
Aprendizagem profissional de treinadores de tênis: um ensaio para primeiras aproximações com o contexto nacional de formação
}

\author{
Tennis coches' professional learning: an essay for the approximation to the national context
}

\author{
Caio Corrêa Cortela ${ }^{1,2}$, Cesar Kist ${ }^{2}$, Michel Milistetd ${ }^{3}$, Jorge Both ${ }^{4}$, Carlos Adelar Abaide Balbinotti ${ }^{1}$ \\ ${ }^{1}$ Universidade Federal do Rio Grande do Sul (UFRGS), Porto Alegre/RS, Brasil \\ ${ }^{2}$ Confederação Brasileira de Tênis (CBT), Florianópolis/SC, Brasil \\ 3 Universidade Federal de Santa Catarina (UFSC), Florianópolis/SC, Brasil \\ ${ }^{4}$ Universidade Estadual de Londrina (UEL), Londrina/PR, Brasil
}

\section{HISTÓRICO DO ARTIGO \\ Recebido: 18 abril 2020}

Aprovado: 13 maio 2020

\section{PALAVRAS-CHAVE:}

Treinadores; Tênis; Aprendizagem Profissional.

\section{KEYWORDS:}

Coaches; Tennis; Professional Learning.

\section{RESUMO}

INTRODUÇÃO: No Brasil, pesquisas referentes ao desenvolvimento do treinador são recentes. Nos últimos cinco anos observam-se os primeiros movimentos para a formação de grupos de pesquisa especificamente ligados à temática.

OBJETIVO: Na tentativa de contribuir nesse cenário, este ensaio bibliográfico, de caráter exploratório, busca apresentar o panorama atual de oportunidades de aprendizagem em contexto formal e não formal, disponíveis aos treinadores brasileiros de tênis em seu processo de aprendizagem profissional.

RESULTADOS: Alguns dilemas encontrados na formação inicial, por meio da via acadêmica e na continuada, pelas vias acadêmica e federativa, são apresentados e debatidos com a literatura.

CONCLUSÃO: Por fim, possíveis avanços frente aos impasses percebidos são sugeridos, visando contribuir com as instituições envolvidas na formação de treinadores da modalidade.

\section{ABSTRACT}

BACKGROUND: In Brazil, research on coaches' development is recent. In the last five years, efforts were made to organize the first research groups concerned to study coaches' development.

OBJECTIVE: In attempt to contribute in this scenario, this exploratory bibliographic essay aims to present the current panorama of learning opportunities available to Brazilian tennis coaches in formal and non-formal context.

RESULTS: Dilemmas in the academic initial training as well as in the continuing training through the academic and federative path are presented and discussed with the current literature.

CONCLUSION: Finally, suggestions to overcome the current stalemates are presented to contribute to the organizations involved on tennis coaches' training and development. 


\section{INTRODUÇÃo}

A compreensão dos meios pelos quais os profissionais aprendem a ser treinadores pode ser considerada o ponto de partida para a análise de programas de formação, que visam contribuir no processo de desenvolvimento desses profissionais. Para gerar momentos/espaços favoráveis à aprendizagem é preciso compreender, de forma holística, como esse processo vem ocorrendo e em determinados contextos e de forma específica para os treinadores de cada modalidade (TRUDEL; CULVER; WERTHNER, 2013). Particularmente, a formação de treinadores de tênis em âmbito internacional, de acordo com Fuentes e Villar (2004), tem ocorrido por três vias distintas: a federativa (Federação Internacional de Tênis - ITF ou pelas confederações e federações); a universitária ou acadêmica; e as formações obtidas por meio das associações privadas.

Visando contribuir com o processo de desenvolvimento profissional de treinadores brasileiros de tênis, o presente estudo procurou contextualizar as oportunidades de aprendizagem, em contextos formal e não formal, existentes no cenário nacional. A fim de proporcionar elementos para delimitação do pano de fundo em que essas aprendizagens ocorrem, este ensaio, de cunho bibliográfico e exploratório, analisou: o cenário relativo à formação inicial e à legislação vigente; e as oportunidades de formação continuada, por meio da via acadêmica e federativa.

Com base no quadro atual de oportunidades pelos quais esses profissionais podem aprender, bem como dos desafios observados até o momento nessas iniciativas, acredita-se que esse ensaio possa contribuir com as instituições envolvidas na formação de treinadores de tênis, uma vez em que apresenta um primeiro olhar sobre as especificidades do contexto nacional (CORTELA et al. 2016). Ao longo do ensaio são apresentadas algumas sugestões para solução de impasses percebidos.

\section{O SISTEMA DE FORMAÇÃO DE TREINADORES DE TÊNIS NO BRASIL}

\section{A formação inicial de treinadores de tênis}

Especificamente no Brasil a intervenção do treinador esportivo e, consequentemente, a do treinador de tênis, apresenta-se como um dos campos de atuação do profissional de Educação Física, independentemente do contexto de ação, ou seja, tanto para aqueles que atuam no esporte de participação ou no de rendimento. Desde a aprovação da Lei $N^{\circ}$. 9.696/1998, que regulamenta o exercício do profissional de Educação Física no país, para atuar no campo esportivo é requerida a obtenção do título de Bacharel em Educação Física (BRASIL, 1998; MILISTETD et al., 2014).

Essa particularidade faz com que a formação inicial de treinadores no Brasil, do ponto de vista legal, ocorra apenas por uma via: a universitária ou acadêmica. Dois casos são exceções e encontram-se amparados pela legislação brasileira: i. o dos treinadores que já atuavam na área anteriormente à promulgação da Lei N. ${ }^{\circ}$ 9.696/1998, aos quais após a comprovação legal de experiência e participação de um programa de instrução oferecido pelos Conselhos Federal e/ou Regional de Educação Física, é garantido o título de "Provisionado" e o direito de atuarem com a modalidade esportiva específica na qual comprovaram experiência; ii. o segundo caso, que diz respeito principalmente aos treinadores de futebol, aos quais a Lei $\mathrm{N}^{\circ}$. 8.650/1993 assegura o direto de exercício profissional no âmbito do treinamento dessa modalidade, desde que possam comprovar experiência de trabalho na área (MILISTETD et al., 2015).

Se, por um lado, a exigência de formação em nível superior no bacharelado em Educação Física, com um mínimo 3.200 horas (MILISTETD et al., 2015), com a necessidade de uma licença anual expedida pelo Conselho Regional de Educação Física (CREF) para o exercício profissional e associada ao reconhecimento legal da profissão de treinador no Brasil, pode ser considerada uma conquista histórica para área, por outro, questiona-se até que ponto essa formação inicial tem efetivamente contribuído na melhoria da formação dos treinadores nacionais.

Da forma como se encontram organizados, os cursos nacionais de graduação em Educação Física apresentam um caráter generalista, visando formar profissionais versáteis, capazes de atender as distintas demandas do mercado, para diferentes modalidades esportivas tais como gestão, lazer, saúde, rendimento, entre outros (MILISTETD et al., 2014). Essas características formativas têm presentado fragilidades e se mostrado insuficientes para a formação do treinador esportivo, especialmente aqueles interessados em trabalhar com esporte de rendimento (MILISTETD et al., 2014; RODRIGUES, 2014).

Os currículos das universidades têm demando pouca atenção às disciplinas relacionadas diretamente ao coaching esportivo, bem como as estratégias experienciais de aprendizagem (MILISTETD et al., 2014). Nesse cenário, o que se observa é um distanciamento e a ausência de relações entre os saberes produzidos e ensinados no meio acadêmico e aqueles necessários ao exercício profissional dos treinadores, colocando-se em pauta a necessidade de se repensar o formato atual desses cursos no que tange a formação do treinador esportivo (CAVAZI et al., 2013; RODRIGUES, 2014).

De acordo Stoszkowski e Collins (2016), mais do que questionar a importância das aprendizagens formais para o desenvolvimento profissional, o que parece estar em xeque para os treinadores é a qualidade e a forma com a qual o processo tem ocorrido. Assim Milistetd et al. têm proposto uma série de reflexões para ressignificar as aprendizagens formais no ambiente universitário, passando pela: modificação do papel do aluno (2018b); por uma estruturação dos Projetos Pedagógicos de Curso (PPC) (2017); pela adoção de estilos de ensino produtivos e redução da quantidade de conteúdos abordados nas aulas teórico/práticas, pela liderança que dê suporte durante as atividades no Estágio, potencializando a experimentação e a reflexão, e pela ampliação de possibilidades de atuação por meio das Atividades Acadêmico-Científico-Culturais (AACC) (2018a).

Especificamente para os treinadores de tênis, a formação inicial parece enfrentar desafios ainda maiores. Mesmo presente na Base Nacional Curricular Comum (BNCC), junto às modalidades de rede/quadra, dividida ou parede de rebote (BRASIL, 2017), a disciplina tênis encontra-se fora do currículo da maior parte dos cursos de graduação em Educação Física no Brasil. De acordo com Milistetd et al. (2014), apenas 10\% das Instituições de Ensino Superior (IES) federais ofertam essa disciplina. A falta de profissionais habilitados para trabalharem com o tênis no meio acadêmico. Os principais argumentos dos coordenadores 
e conselhos de curso para não ofertarem a disciplina está a concepções de o tênis ser considerado um esporte elitista e também a falta de materiais e quadras específicas (DIAS et al., 2002)

Apesar dessa reduzida oferta, a formação inicial para treinadores de tênis tem se associado a uma maior autopercepção de competência profissional. De modo geral, os profissionais graduados relataram maior percepção de domínio dos conhecimentos relativos a biodinâmica e a teoria e metodologia do treinamento esportivo. Nessa mesma direção, verificou-se níveis mais elevados de autopercepção de domínio das competências de planejamento e comunicação, consideradas basilares para o exercício profissional dos treinadores, independentemente do contexto no qual atuam (CORTELA et al., 2017).

Portanto, consideramos que nesse momento de reformulação das Diretrizes Curriculares Nacionais dos cursos de graduação em Educação Física, estabelecidas pela Resolução $N^{\circ}$. 6, de 18 de dezembro de 2018, seria importante a aproximação de pesquisadores, da Confederação Brasileira de Tênis (CBT), e/ou federações estaduais, junto as IES, para compreender quais os entraves atuais para inserção da modalidade na grade curricular e como as demais instituições envolvidas no desenvolvimento profissional de treinadores poderiam contribuir com as IES nesse processo.

\section{A FORMAÇÃO CONTINUADA DE TREINADORES DE TÊNIS}

No que se refere a formação continuada de treinadores de tênis no Brasil, esta pode ocorrer por três vias: a acadêmica ou universitária, em cursos de pós-graduação; a federativa, promovida pela CBT e pelas federações estaduais; e a associativa, realizada por meio e associações.

\section{Por meio da via acadêmica}

Apesar de existirem opções por meio da via acadêmica para a formação continuada no Brasil, como alguns cursos de especialização em tênis, observa-se que esse caminho ainda apresenta pouca representatividade junto aos treinadores. Dois fatores parecem contribuir para esse cenário. 0 primeiro diz respeito ao período de transição profissional vivenciado pela atual geração de treinadores nesta modalidade. Anteriormente à promulgação da lei que regulamentou a atuação do profissional de Educação Física, em 1998, e consequentemente, a dos treinadores de tênis, não se exigia qualquer tipo de formação inicial para o exercício profissional nessa área.

Mesmo não havendo pesquisas de âmbito nacional que apresentem um panorama geral da formação de treinadores no país, com base nos resultados dos estudos publicados até o momento, é possível observar que boa parte dos profissionais que já atuavam anteriormente a regulamentação da profissão apresentam, como nível máximo de formação, os ensinos Fundamental ou Médio (CORTELA, et al., 2013a). Os resultados com treinadores paranaenses (CORTELA, et al., 2013a) e catarinenses (LIMA et al., 2014), apontam ainda que, atualmente, grande parte dos treinadores inseridos no mercado de trabalho é composta por profissionais 'Provisionados'.

Segundo a Lei de Diretrizes de Bases N. 9.394/1996, o acesso aos cursos de Pós-graduação no Brasil é restrito aos profissionais portadores de diplomas de cursos de nível superior, o que impossibilita a participação de profissionais Provisionados em atividades de formação continuada por meio da via acadêmica (BRASIL, 1996), contribuindo para a baixa participação dos treinadores de tênis em formações continuadas por meio dessa via.

Além desse fator, a necessidade de formação em nível superior traz consigo uma mudança na forma como os treinadores veem as instituições responsáveis pelas atividades de formação. Segundo Gomes et al. (2011), a formação anterior dos treinadores interfere diretamente na forma como os mesmos avaliam as entidades responsáveis por ministrarem as atividades de formação. Enquanto os profissionais sem formação acadêmica tendem a supervalorizar as atividades de formação de cunho federativo, os treinadores com formação em nível superior creditam o mesmo peso para as atividades de formação desenvolvidas por meio das diferentes vias, sejam essas as IES, as federações ou demais entidades oficialmente reconhecidas.

Assim, esperasse que a tendência de aumento no número de treinadores graduados em Educação Física, decorrente da obrigatoriedade da formação em nível superior no Bacharelado (CORTELA et al., 2019b), associada ao maior reconhecimento dado pelos profissionais com formação acadêmica às atividades de formação decorrentes da via universitária e da maior autopercepção de domínio em competências consideradas centrais por parte de treinadores graduados (CORTELA et al., 2017), possam contribuir para o aumento na frequência de participação em atividades de formação continuada por meio dessa via.

\section{Por meio da via federativa}

No caso concreto dos treinadores de tênis, as formações ocorridas no contexto não formal (NELSON et al., 2006), ofertadas por meio da via federativa, têm recebido maior atenção em todo o mundo (FUENTES; VILLAR, 2004). Particularmente no Brasil, esse comportamento também tem sido relatado em diferentes estudos (CORTELA et al. 2013a; 2019b; 2020; LEITE et al., 2016; LIMA et al., 2014). Em geral, as titulações expedidas nesse âmbito apresentam-se divididas em três ou quatro módulos, sendo que as cargas horárias, os pré-requisitos e os conteúdos de cada módulo variam de um país para outro (FUENTES; VILLAR, 2004). Segundo Sanz, Fuentes e Villar (2004) os países em desenvolvimento costumam optar pelo modelo de formação de treinadores estabelecido pela ITF. Ele é composto por três níveis de formação: um primeiro destinado ao trabalho com tenistas iniciantes ou com nível intermediário de jogo; o segundo destinado a tenistas avançados; e último nível destinado aos treinadores interessados em trabalhar com tenistas de alto rendimento.

No Brasil, o marco para a formação continuada realizada por meio da via federativa foi a criação do Departamento de Capacitação (DC) de treinadores da CBT, em 1997. Até aquele momento ainda não havia uma estrutura que desse suporte à formação de treinadores no país, verificando-se o predomínio de cursos de curta duração, com temas específicos ministrados por treinadores de prestígio e reconhecimento junto aos pares. De modo geral, a estrutura de funcionamento do DC da CBT pode ser dividida em dois períodos. De 1997 a 2004 as atividades de formação continuada eram distribuídas em quatro níveis, denominados de Níveis 1, 2, 3 e 4. Contando com uma carga horária de 40 horas de duração para cada nível, os cursos eram realizados ao longo de quatro dias e, juntos, totalizavam 
160 horas de formação.

Nesse período, o curso de Nível 3 da ITF ainda não havia sido criado. Dessa forma, observou-se que os conteúdos abordados nos cursos ofertados pelo DC eram os mesmos apresentados pela ITF em seus cursos de Nível 1 e 2 . Com exceção do curso de Nível 1, que era aberto a todos os interessados, os demais (Níveis 2, 3 e 4) exigiam a aprovação nos módulos anteriores como pré-requisito à participação (CORTELA, 2009). Para aprovação nos cursos os candidatos eram submetidos a avaliações teóricas e práticas, relacionadas aos conteúdos especificamente abordados.

Outra característica a ser destacada desse período refere-se ao número de profissionais que ministravam os cursos oferecidos pelo departamento. De 1997 a 2004 apenas dois profissionais ficaram responsáveis pela realização dos cursos no país. Esses demonstravam experiência como treinadores nos mais distintos âmbitos de atuação, porém não apresentavam formação universitária na área. Com as mudanças ocorridas na direção da CBT e, consequentemente no DC, houve uma reformulação no formato de trabalho adotado nesse pilar a partir de 2005. O primeiro aspecto a ser destacado foi a presença de um maior número de profissionais envolvidos na condução dos cursos. Até o mês de março do ano de 2020 o DC contava com um Coordenador e um Assistente Técnico que, somados a mais 17 profissionais, compunham a Equipe Nacional responsável por ministrar as atividades de formação (CBT, 2020a).

Como base nas informações disponibilizadas pelo Sistema Nacional de Graduação Profissional (SNGP) e pelo Conselho Federal de Educação Física é possível observar que o perfil dos profissionais que atuam no departamento é composto em sua maioria por treinadores Provisionados (12), seguido de treinadores com pós-graduação em Educação Física ou áreas afins (6) ou graduação (1) na área.

Esse perfil mais heterogêneo dos treinadores responsáveis pelas formações e a presença de profissionais de diversas regiões do país, Sudeste (7), Sul (6), Nordeste (4) e Centro-Oeste (2), parece ser fundamental para o melhor entendimento das necessidades locais de formação e para que essas atividades possam se aproximar ao máximo da realidade encontrada pelos treinadores no exercício profissional (CBT, 2020a).

No que refere as proposições adotadas pelo DC para estruturação do Sistema de Formação de Treinadores (SFT) nacional, verifica-se que o mesmo continuou atrelado às diretrizes do modelo proposto pela ITF, no entanto, a distribuição dos conteúdos e das cargas horárias ganharam novas configurações. Os conteúdos dos cursos de Nível 1 e 2 da ITF, anteriormente distribuídos em quatro níveis no Brasil foram agrupados em módulos, denominados de Módulos A, B, C, D, E, F e G. Com essa modificação, a carga horária para cada módulo foi reduzida de 40 horas para 25 horas, observando-se, entretanto, um aumento no número total de horas dedicados a formação, passando de 160 horas para 175 horas (2020b).

Com a lançamento do curso de Nível 3 pela ITF, novos módulos foram introduzidos no sistema nacional. Esses foram denominados de Módulos Avançados e foram divididos em cinco cursos com temáticas específicas: Tática e Metodologia; Biomecânica; Planificação e Desenvolvimento do tênis; Preparação Física; e Psicologia (2020b).

Além desses, atualmente o modelo nacional ainda dispõe de mais quatro cursos específicos: Play and Stay; Curso para Professores e Administradores de Clubes e Academias; Tennis Xpress; e o Módulo Escolar. Somados a eles são realizados os Workshops Internacionais, as Giras Nacionais, os Encontros Nacionais, os Cursos Curtos e outras ações temáticas com menor frequência.

A oferta de aproximadamente 350 horas de formação presente no SFT e de 12 cursos de certificação, coloca a CBT como umas das confederações olímpicas mais ativas do país, no que diz respeito à formação continuada de treinadores (MILISTETD et al., 2016). O Quadro 1 apresenta um resumo da estrutura atual de cursos de formação de treinadores oferecido pelo departamento, com os seus respectivos conteúdos e formato de avaliação.

Uma breve análise do SFT oferecida pela CBT permite constatar que a estrutura atual se encontra claramente alinhada à proposta da ITF, contemplando todos os conteúdos e cargas horárias estipulados nos Níveis 1, 2 e 3 (2020c). O modelo nacional ainda atende de forma satisfatória a todos os critérios estabelecidos pela Comissão de Treinadores da ITF (2014) e, por esse motivo, conjuntamente com 17 outras nações, o DC da CBT recebeu a certificação Ouro da entidade (ITF, 2019a). São eles:

1. Possuir um Departamento de Formação de Treinadores incorporado à estrutura da confederação nacional, e contar com uma Comissão de Treinadores e/ou profissionais vinculados as Ciências do Esporte;

2. Dispor de um Diretor/Coordenador de Capacitação de Treinadores e de uma equipe capacitada, que inclua os tutores responsáveis por ministrarem os cursos, e/ou tutores ligados as Ciências do Esporte;

3. Dispor de um programa/estrutura para a formação de treinadores baseado em competências;

4. Dispor de um calendário/agenda e realizar regularmente atividades de formação, como: cursos; seminários; oficinas; conferências; entre outros, para treinadores e demais profissionais ligados ao tênis;

5. Contar com um programa de licenças para os treinadores, por meio do qual os mesmos recebam uma autorização (licença profissional anual), que lhes permita trabalhar com o tênis no país;

6. Criar ou utilizar uma série de recursos para formação de treinadores (livros, vídeos, DVDs, internet, entre outros), em seu idioma oficial;

7. Contar com um programa de desenvolvimento profissional para a formação continuada.

Esse alinhamento e reconhecimento por parte da ITF ao SFT nacional, garante aos treinadores brasileiros a equivalência das formações realizadas no país às expedidas pela própria instituição. Segundo os dados disponibilizados para a presente pesquisa pelo DC da CBT, no final de março de 2020, de 2005 a 2019 foram realizadas 695 ações de formação continuada no país, as quais contabilizaram 16.584 participantes.

Dessas participações, 3.146 treinadores conseguiram concluir a carga horária requerida para a certificação equivalentes aos Níveis 1, 2 ou 3 da ITF. A Figura 1 apresenta um resumo das formações realizadas no país nesse período e do número de treinadores com certificações. 
Quadro 1. Estrutura atual dos cursos de formação oferecidos pelo DC da CBT.

\begin{tabular}{|c|c|c|c|c|c|}
\hline Curso & $\begin{array}{l}\mathrm{C} / \mathrm{H} \\
\text { (h) }\end{array}$ & Descrição dos conteúdos abordados & $\begin{array}{l}\text { Pré- } \\
\text { requisitos }\end{array}$ & Avaliação & SNGP \\
\hline Módulo A & 25 & $\begin{array}{l}\text { Play and Stay (exercícios e jogos); ensino para iniciantes; exercícios de desenvolvimento motor; intro- } \\
\text { dução dos golpes básicos; desenvolvimento físico para crianças e jovens; princípios táticos do jogo de } \\
\text { tênis; psicologia para crianças; e o papel do professor. }\end{array}$ & Não há & $\begin{array}{l}\text { Teórica e } \\
\text { prática }\end{array}$ & 20 pontos \\
\hline Módulo B & 25 & $\begin{array}{l}\text { Estrutura da aula individual; golpes básicos (empunhaduras, preparação, terminação e posições de } \\
\text { pernas); utilização dos lançamentos e cestos de bolas; tática e estratégia para o jogo de simples; técni- } \\
\text { cas de correção e melhoras; os efeitos e trajetórias da bola; regras de tênis e organização de torneios. }\end{array}$ & Não há & $\begin{array}{l}\text { Teórica, } \\
\text { prática, } \\
\text { nível de } \\
\text { jogo e lan- } \\
\text { çamentos }\end{array}$ & 20 pontos \\
\hline Módulo C & 25 & $\begin{array}{l}\text { Aula em grupo com progressões dos golpes de fundo/voleios/ saque/devolução; organização e distri- } \\
\text { buição de alunos na aula em grupo; aula em grupo com jogadores de diferentes níveis; atenção indi- } \\
\text { vidual na aula em grupo; liderança e comunicação na aula em grupo; preparação física; ITN (Número } \\
\text { Internacional de Tênis); tênis em cadeira de rodas; tênis para pessoas com deficiência intelectual; } \\
\text { equipamentos de tênis; princípios táticos do jogo de duplas, posicionamentos e diferentes formações. }\end{array}$ & Não há & $\begin{array}{l}\text { Teórica e } \\
\text { prática }\end{array}$ & 20 pontos \\
\hline Módulo D & 25 & $\begin{array}{l}\text { A metodologia do ensino; a comunicação com o jogador; etapas do processo de aprendizagem; como } \\
\text { jogar contra os diferentes estilos de jogo; exercícios táticos de simples e duplas; a antecipação no jogo } \\
\text { de tênis; jogo de porcentagens; o "momento" do jogo; análise tática das partidas. }\end{array}$ & Não há & $\begin{array}{l}\text { Teórica e } \\
\text { prática }\end{array}$ & 20 pontos \\
\hline Módulo F & 25 & $\begin{array}{l}\text { A planificação da carreira do jogador; o desenvolvimento do jogador nas diferentes etapas e idades; } \\
\text { como fazer a análise do jogador; o estabelecimento de objetivos; a planificação do treinamento; perio- } \\
\text { dização; a sessão de treinamento e estruturação de exercícios. }\end{array}$ & Não há & $\begin{array}{l}\text { Teórica e } \\
\text { prática }\end{array}$ & 20 pontos \\
\hline Módulo G & 25 & $\begin{array}{l}\text { A preparação física no tênis (demanda energética do tênis, potência, agilidade, treinamento aeróbico } \\
\text { para tenista); o acompanhamento dos jogadores em torneios; o treinamento de jogadoras; a nutrição } \\
\text { para o tenista; prevenção de lesões; e o treinamento mental (concentração, motivação, controle emo- } \\
\text { cional, autoconfiança e rotinas). }\end{array}$ & Não há & Teórica & 20 pontos \\
\hline $\begin{array}{l}\text { Módulo } \\
\text { Avançado Tática } \\
\text { e Metodologia }\end{array}$ & 25 & $\begin{array}{l}\text { Introdução a táticas avançadas; princípios táticos do tênis de alto nível; estilos de jogo tático do tênis } \\
\text { moderno; tática de jogo no tênis feminino; táticas em diferentes superfícies; análise e estatística de } \\
\text { partidas; tática de duplas para jogadores avançados; metodologia de treinamento para o tênis avança- } \\
\text { do; aprendizagem das habilidades motoras para o alto nível. }\end{array}$ & $\begin{array}{l}\text { Aprovação } \\
\text { nos } \\
\text { Módulos } \\
\text { A, B e C, ou } \\
\text { no extinto } \\
\text { Nível } 1 \text { CBT }\end{array}$ & $\begin{array}{l}\text { Teórica e } \\
\text { prática }\end{array}$ & 20 pontos \\
\hline $\begin{array}{l}\text { Módulo } \\
\text { Avançado } \\
\text { Biomecânica }\end{array}$ & 25 & $\begin{array}{l}\text { Biomecânica e técnicas avançadas; a aceleração da cabeça da raquete; velocidade linear e angular; } \\
\text { biomecânica do movimento em quadra; carga e produção do golpe; análise de produção dos golpes } \\
\text { - quantitativo/qualitativo; modelos de desempenho biomecânico; atividade muscular e sua impor- } \\
\text { tância. }\end{array}$ & $\begin{array}{l}\text { Aprovação } \\
\text { nos } \\
\text { Módulos } \\
\text { A, B e C, ou } \\
\text { no extinto } \\
\text { Nível } 1 \text { CBT }\end{array}$ & $\begin{array}{l}\text { Teórica e } \\
\text { prática }\end{array}$ & 20 pontos \\
\hline $\begin{array}{l}\text { Módulo Avança- } \\
\text { do Planificação/ } \\
\text { Desenvolvimen- } \\
\text { to do tênis }\end{array}$ & 25 & $\begin{array}{l}\text { Plano de desenvolvimento do jogador; destrezas profissionais para treinadores avançados - liderança, } \\
\text { administração, organização, desenvolvimento profissional, marketing no tênis; comunicação e infor- } \\
\text { mática; criação e implantação de um plano para o desenvolvimento do tênis; comercialização e pro- } \\
\text { moção do tênis; plano de desenvolvimento de recursos; diferentes programas de tênis; calendário de } \\
\text { torneios. }\end{array}$ & $\begin{array}{l}\text { Aprovação } \\
\text { nos } \\
\text { Módulos } \\
\text { A, B e C, ou } \\
\text { no extinto } \\
\text { Nível } 1 \text { CBT }\end{array}$ & $\begin{array}{l}\text { Teórica e } \\
\text { prática }\end{array}$ & 20 pontos \\
\hline $\begin{array}{l}\text { Módulo } \\
\text { Avançado } \\
\text { Preparação } \\
\text { Física }\end{array}$ & 25 & $\begin{array}{l}\text { Avaliação fisiológica do tenista; desenvolvimento atlético a longo prazo; princípios do treinamento; } \\
\text { coordenação; flexibilidade; resistência aeróbia/anaeróbica; desenvolvimento da força; potência no } \\
\text { tênis; velocidade e agilidade; mecânica do movimento; trabalho durante os torneios; recuperação. }\end{array}$ & $\begin{array}{l}\text { Aprovação } \\
\text { nos } \\
\text { Módulos } \\
\text { A, B e C, ou } \\
\text { no extinto } \\
\text { Nivel } 1 \text { CBT }\end{array}$ & $\begin{array}{l}\text { Teórica e } \\
\text { prática }\end{array}$ & 20 pontos \\
\hline $\begin{array}{l}\text { Módulo } \\
\text { Avançado } \\
\text { Psicologia }\end{array}$ & 25 & $\begin{array}{l}\text { Treinamento mental para jogadores avançados; fixação de metas; destrezas psicológicas para jogado- } \\
\text { res de alto nível; motivação; técnicas de concentração, controle emocional; controle de pensamentos; } \\
\text { rotinas psicológicas; desempenho psicológico em competição; imagens/visualização; desenvolvimen- } \\
\text { to psicológico e planificação. }\end{array}$ & $\begin{array}{l}\text { Aprovação } \\
\text { nos } \\
\text { Módulos } \\
\text { A, B e C, ou } \\
\text { no extinto } \\
\text { Nível } 1 \text { CBT }\end{array}$ & $\begin{array}{c}\text { Teórica e } \\
\text { prática }\end{array}$ & 20 pontos \\
\hline Play and Stay & 8 & $\begin{array}{l}\text { Apresentação do programa Play and Stay; como utilizar os diferentes tipos de bola e tamanho de qua- } \\
\text { dras; como tornar o tênis fácil; divertido e saudável; trabalho técnico/tático com jogadores iniciantes; } \\
\text { golpes básicos - ensino por progressões; ensino através do jogo; exercícios de desenvolvimento motor; } \\
\text { tênis e os seus benefícios à saúde. }\end{array}$ & Não há & Não há & 6 pontos \\
\hline $\begin{array}{l}\text { Curso para } \\
\text { professores e } \\
\text { administradores } \\
\text { de clubes e } \\
\text { academias }\end{array}$ & 15 & $\begin{array}{l}\text { Por que as pessoas vêm jogar tênis e param de jogar tênis?; o Play and Stay no Brasil e no mundo; } \\
\text { dinâmicas e jogos em grupo; habilidades necessárias para um professor trabalhar com a iniciação; o } \\
\text { tênis e seus beneficios para a saúde; tênis um esporte para todos, ITN (Número Internacional do Tênis), } \\
\text { circuitos regionais e nacionais; diferentes formatos de competição; relação professor/administrador } \\
\text { - trabalho em equipe; o bom funcionamento de uma escola de tênis; ações de promoção do tênis; } \\
\text { marketing do tênis. }\end{array}$ & Não há & Não há & 9 pontos \\
\hline Tennis Xpress & 7 & $\begin{array}{l}\text { A introdução do tênis para adultos iniciantes; apresentação do curso Tennis Xpress de } 9 \text { horas; o uso } \\
\text { das diferentes progressões de bola e quadra; organização da aula em grupo; o trabalho com alunos } \\
\text { de diferentes níveis; organização de jogos com adultos; iniciativas para os alunos darem continuidade } \\
\text { no tênis. }\end{array}$ & Não há & Não há & 6 pontos \\
\hline Módulo Escolar & 16 & $\begin{array}{l}\text { Justificativa do programa; por que o tênis nas escolas; filosofia do programa; material necessário para } \\
\text { a implantação; metodologia de ensino; mini tênis; aspectos pedagógicos; aspectos administrativos e } \\
\text { jurídicos; principais obstáculos à implantação e como superá-los; abordagem à célula receptora - di- } \\
\text { reitos, deveres e benefícios; estratégias de divulgação e captação de alunos; adequação dos espaços e } \\
\text { organização dos alunos; plano de aulas; lidando com diferentes níveis na mesma aula; eventos inter- } \\
\text { nos e externos; avaliações; relatórios e reuniões com os pais; encaminhamento dos alunos às células } \\
\text { receptoras. }\end{array}$ & Não há & Teórica & 12 pontos \\
\hline
\end{tabular}

Fonte: Adaptado pelos autores - a terminologia utilizada na descrição dos conteúdos foi mantida conforme documento original (CBT, 2020b). 


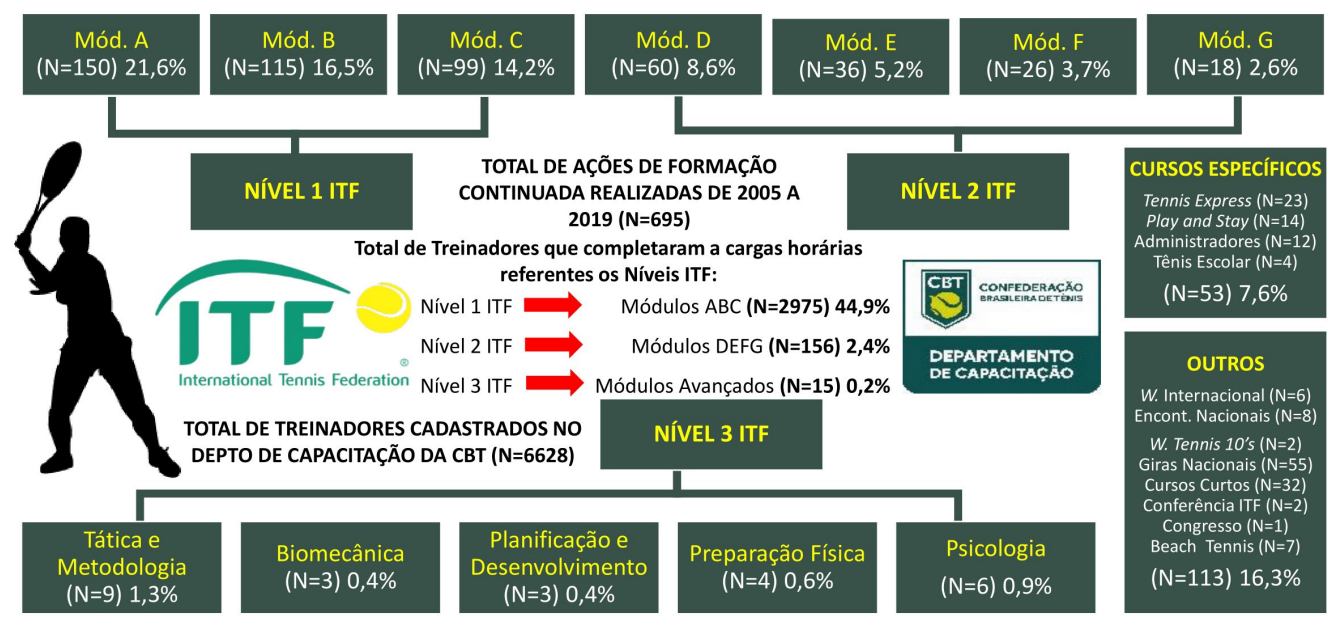

Figura 1. Quadro geral de ações de formação e treinadores certificados no Brasil pelo Departamento de Capacitação.

Fonte: Elaborado pelos autores com base nas informações recebidas pelo DC da CBT.

O interesse por diferentes ações de formação, e em especial, pelos Módulos A, B e C reforçam o interesse pessoal dos treinadores em conhecimentos específicos do tênis e a necessidade de que as instituições responsáveis pela formação de treinadores no contexto não formal sejam capazes de promover um ambiente propício, que estimule e seja significativo para quem aprende (TRUDEL et al., 2013). Além disso, esses módulos tratam de conhecimentos básicos técnico-táticos e pedagógicos da modalidade que poderiam ser desenvolvidos na formação universitária acadêmica, todavia não são ofertadas na maioria dos cursos de bacharelado em Educação Física (Milistetd et al., 2014), criando grande demanda aos cursos federativos. De modo geral, os conteúdos e a carga horária desses módulos correspondem ao curso Nível 1 da ITF ( 80 horas). Por se tratar dos módulos introdutórios do programa, o foco dessas formações encontra-se direcionado a conhecimentos e habilidades profissionais básicos para o exercício profissional no contexto de participação (tenistas iniciantes ou com nível intermediário de jogo) (ITF, 2019b).

A menor incidência de participação nos níveis mais elevados do programa nacional, também evidenciada em estudos aplicados (CORTELA et al., 2013a; 2019b; LEITE et al., 2016; LIMA et al., 2014), aponta para alguns cenários. Uma primeira possibilidade é a de que a capacitação ofertada nas primeiras etapas do processo tem proporcionado o suporte necessário para a inserção do treinador no tênis e/ou para atuação no contexto de participação, cenário no qual atua a maior parte dos profissionais da modalidade (CORTELA et al., 2013b).

Por outro lado, sabendo que o processo de desenvolvimento profissional do treinador esportivo tem sido defendido pela literatura como algo a ser constantemente praticado ao longo de toda a vida (TOZETTO et al., 2017), e considerando a complexidade da intervenção desse profissional (ICCE, 2013), entende-se que essas 75 horas de formação não sejam suficientes para atenderem de forma satisfatória todas a competências requeridas, levando o debate para um outro fator que poderia contribuir com esse quadro.

De acordo com Tozetto et al. (2017), as experiências vivenciadas durante a trajetória profissional influenciam o olhar dos treinadores quanto as fontes de aprendizagem empregadas em seu desenvolvimento. Nesse sentido, o contexto de intervenção profissional aparece como um elemento chave, contribuindo no processo decisório de seleção dos treinadores por determinadas oportunidades de aprendizagem (ROCCHI; COUTURE, 2018).

Da forma como se encontram organizados, os conteúdos e competências propostos nos Módulos D, E, F e G e Avançados (Quadro 1), correspondem aos descritos para o Nível 2 (80 horas) e Nível 3 ( 88 horas) da ITF, sendo orientados as especificidades do trabalho com tenistas avançados e de alto rendimento (CBT, 2020c; ITF, 2019b). Essa estrutura linear de organização curricular, acompanha e busca responder às demandas do processo de formação esportiva em longo prazo dos atletas, em que as primeiras etapas focam as atenções para o processo de iniciação esportiva e a entrada na carreira como treinador e as últimas formações são voltadas ao trabalho com o tênis de alto rendimento.

Apesar de muitos conhecimentos e competências considerados centrais para o treinador (ICCE, 2013) serem abordadas de forma mais enfática nesses módulos, como: a comunicação e as metodologias de ensino (D); a avalição dos aspectos técnicos e biomecânicos (E); e o estabelecimento de objetivos e o planejamento da sessão de treino (F), por exemplo (CBT, 2020b), essas formações têm recebido menor atenção por parte dos treinadores (CORTELA et al., 2013a; 2019b; LEITE et al., 2016; LIMA et al., 2014), que podem estar associando esses módulos ao trabalho com o tenistas de rendimento e não sendo capazes de vislumbrar a transferência dessas competências para o contexto com o qual atuam.

Dessa forma, parece necessário vislumbrar um novo caminho em que os treinadores que atuam exclusivamente no contexto de participação atribuam maior significado as formações e possam seguir se desenvolvendo, visando tornar-se experts nesse ambiente de intervenção. A proposta da Tennis Canada (2014), baseada nas recomendações do National Coaching Certification Program (NCCP), pode apresentar-se como um ponto de partida para o estabelecimento das diretrizes da formação voltada ao contexto de participação.

A estrutura global do modelo baseia-se em competências e reconhece que a formação de treinadores necessita atender, de 
forma específica, aos diferentes contextos. Dessa forma, observam-se dois caminhos para a formação de treinadores: um voltado à prática do tênis como meio de formação, lazer e saúde, com quatro etapas de formação (Tennis for Life); e outro destinado à formação de treinadores para trabalhar com o esporte de rendimento, com seis etapas (Competition Stream).

Independentemente do contexto com o qual pretende atuar, as duas primeiras etapas são comuns, garantido o alinhamento inicial dos profissionais formados pelo programa (TENNIS CANADA, 2014), estratégia que pode vir a ser empregada no STF nacional atual, sem modificações significativas na estrutura curricular vigente. Assim como observado para a formação inicial, o envolvimento em ações de formação continuada por meio da via federativa se associou a uma maior autopercepção de domínio em competências consideradas essenciais para o exercício profissional do treinador, como o planejamento e a avaliação da sessão de treino (CORTELA et al., 2019a).

\section{CONCLUSÃO}

A partir do momento em que se trabalha com a formação de treinadores em um país com as dimensões do Brasil, passa a ser necessário conhecer com profundidade o perfil dos profissionais que atuam com a modalidade e as diferenças regionais existentes. O momento de transição vivido pela atual geração de treinadores de tênis predispõe ao aparecimento de profissionais com processos de formação e desenvolvimento muito distintos, o que requer das instituições responsáveis pelas atividades de formação opções também heterogêneas, que possam atender as necessidades e expetativas de quem aprende.

Mesmo com o reconhecimento da ITF sobre a estrutura atual do SFT do DC da CBT, e do interesse dos treinadores por ações de formação desenvolvidas pela via federativa, verifica-se que essa é uma das opções de formação existentes no país. Nesse sentido, parece fundamental debater com maior frequência o processo de formação e desenvolvimento profissional dos treinadores brasileiros de tênis, de forma em todos os contextos de aprendizagem.

Ao mesmo tempo em que se observa a exigência de formação em nível superior como bacharel em Educação Física para o exercer a profissão como treinador, verifica-se que o tênis se encontra ausente da maior parte dos currículos das universidades brasileiras. Programas de Educação a Distância (EAD), como o que foi anunciado pelo DC recentemente e voltado ao tênis escolar, poderiam ser ofertados como uma alternativa de curto prazo para aproximação da modalidade no meio acadêmico, sendo inseridos em disciplinas gerais como esportes individuais ou alternativos, via Tecnologia de Informação e Comunicação (TIC). Essa alternativa, abre um leque de possibilidades para que qualquer IES possa fazer uso e apresentar a modalidade para os futuros profissionais.

A necessidade de formação em nível superior na área, característica singular do contexto brasileiro, também impacta diretamente as ações de formação continuada ofertadas pela via federativa. O Brasil utiliza como referência, nessa via de formação, o modelo da ITF, o qual considera os cenários em que não há exigência de graduação na área. Assim, a presença de conteúdos na estrutura curricular dessas ações de formação deve ser foco constante de análise e, em caso de necessidade, reajustes para a realidade nacional. Essa atenção pode evitar a sobreposição de conteúdos, apresentados anteriormente na formação inicial e com uma carga horária mais elevada, o que ampliará o tempo destinado ao desenvolvimento de conhecimentos e competências relativos especificamente à atuação profissional do treinador de tênis.

Por fim, é essencial que as entidades responsáveis pela formação dos treinadores, em especial as universidades, a confederação e as federações, se aproximem em prol do crescimento e desenvolvimento da modalidade. A realização de atividades de formação e a criação de projetos de educação e pesquisa compartilhados poderão contribuir para o fortalecimento do SFT nacional, minimizando as lacunas e aproximando o conhecimento científico da realidade e do exercício profissional cotidiano dos treinadores.

\section{REFERÊNCIAS}

BRASIL. Lei $\mathbf{N}^{\circ}$. 9.394, de 20 de dezembro de 1996. Diário Oficial da União, Disponível em: <http://www.planalto.gov.br/ccivil 03/Leis/L9394.htm>. Acessado em: 9 de janeiro de 2015.

BRASIL. Lei $\mathbf{N}^{\circ}$. 9.696, $1^{\circ}$ de setembro de 1998. Diário Oficial da União, Disponível em: <http://www.planalto.gov.br/ccivil_03/leis/19696.htm>. Acessado em: 20 de janeiro de 2015.

BRASIL. Ministério da Educação. Base Nacional Comum Curricular. Brasília: MEC 2017. Disponível em: <http://basenacionalcomum.mec.gov. br/images/BNCC EI EF 110518 versaofinal site.pdf>. Acessado em: 04 outubro de 2019.

CAVAZANI, R. N.; CESANA, J.; DA SILVA, L. H.; CRESSONI, F. E. G.; TAVARES JUNIOR, A. C.; ARANHA, A. C. M.; DRIGO, A. J. O técnico de judô: um estudo comparativo após 10 anos da regulamentação da educação física. Revista Brasileira de Ciência e Movimento, Taguatinga, v. 21, n. 3, p. 105-17, 2013.

CBTa. Confederação Brasileira de Tênis. Departamento de Capacitação de Treinadores. Disponível em: <http://cbt-tenis.com.br/capacitacao. php?cod=2>. Acessado em: 31 de março de 2020.

CBTa. Confederação Brasileira de Tênis. Estrutura dos cursos de formação oferecidos pelo departamento de capacitação. Disponível em: <http://cbttenis.com.br/capacitacao.php?cod=3>. Acessado em: 31 de março de 2020.

CBTa. Confederação Brasileira de Tênis. Perguntas e respostas: qual a comparação dos módulos da CBT com os cursos da ITF. Disponível em:

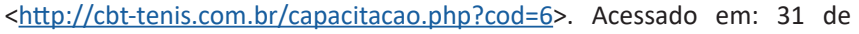
março de 2020 .

CORTELA, C. C. Planeamento de carreira desportiva de jovens tenistas para a alta competição: a transição para a etapa de rendimento máximo. 2009. 96f. Dissertação (Mestrado em Ciências do Desporto e Educação Física) Universidade de Coimbra, Coimbra, 2009.

CORTELA, C. C.; ABURACHID, L. M.; CORTELA, D. N. R.; HAAS, L. G. N. $O$ mercado de trabalho dos treinadores paranaenses de tênis. Revista Eletrônica FAFIT/FACIC, Itararé, v. 4, n. 2, p. 14-25, 2013b.

CORTELA, C. C.; ABURACHID, L. M.; SOUZA; S. P.; CORTELA, D. N. R.; FUENTES, J. P. G. A formação inicial e continuada dos treinadores paranaenses de tênis. Conexões, Campinas, v. 11, n. 2, p. 60-84, 2013a.

CORTELA, C. C.; BALBINOTTI, C. A. A.; TOZETTO, A. V. B.; BOTH, J.; MILISTETD, M. Associação entre formação inicial e autopercepção de competência profissional de treinadores de tênis. Journal of Sport Pedagogy and Research, Rio Maior, v. 3, n. 2, p. 32-42, 2017.

CORTELA, C. C.; GONÇALVES, G. H. T.; KLERING, R. T.; BALBINOTTI, C. A. A. O "estado da arte" das publicações sobre tênis em periódicos nacionais. Coleção Pesquisa em Educação Física, Várzea Paulista, v. 15, n. 2, p. 14351, 2016.

CORTELA, C. C.; MILISTETD, M.; BOTH, J.; GALATTI, L.; CRESPO, M.; BALBINOTTI, C. A. A. Formación permanente y autopercepción de competencia: un estudio con entrenadores de tenis. Pensar em Movimiento, Montes de Oca, n. 17, v. 2, p. 1-18. 2019a. 
CORTELA, C. C.; MILISTETD, M.; GALATTI, L.; BOTH, J; BALBINOTTI, C. A. A. Perfil e desenvolvimento profissional de treinadores de tênis. Caderno de Educação Física e Esporte, Marechal Cândido Rondon, v. 17, n. 1, p. 167-78, 2019b.

DIAS, J. M.; SANTOS, S. G.; SILVA, O. J.; ABES, L. O.; CARABAGIALLE, M. A.; SIQUEIRA, S. G. O ensino e aprendizagem de tênis nos cursos de educação física. In MORO, A. R. P.; DIAS, J. M. In: IV Jornada Internacional de treinamento e organização do tênis. Anais... Florianópolis: NETEC, 2002. p. 105-7.

FUENTES, J. P. G.; VILLAR, F. A. El entrenador de tenis de alto rendimientoun estudio sobre su formación inicial y permanente. Badajoz: APROSUBA-3, 2004.

GOMES, R. E.; ISIDIO, A. S. M.; BATISTA, P. M. F.; MESQUITA, I. M. R. Acesso à carreira de treinador e reconhecimento das entidades responsáveis pela formação: um estudo com treinadores portugueses em função do nível de escolaridade e da experiência profissional. Journal of Physical Education, Maringá, v. 22, n. 2, p. 185-95, 2011.

ICCE. International Council for Coaching Excellence. International Sport Coaching Framework. 2. ed. Champaign: Human Kinetics, 2013.

ITF. International Tennis Federation. Recognition of Coach Education Systems of National Associations. 2014. Disponível em: <http:// en.coaching.itftennis.com/media/152305/152305.pdf>. Acessado em: 04 de janeiro de 2015.

ITF. International Tennis Federation. Coach Education Programme: Educating and certifying coaches. 2019b. Disponivel em: $<$ https://www.itftennis. com/en/news-and-media/articles/itf-coach-education-programme-educating-and-certifying-coaches/>. Acessado em: 03 de janeiro de 2020.

ITF. International Tennis Federation. ITF global tennis report 2019: a report on tennis participation and performance worldwide. International Tennis Federation: London, 2019a.

LEITE, E. V.; CIESLAK, F.; SILVA, C. F.; BALBINOTTI, C. A. A.; CORTELA, C. C. Qualidade de vida, percepção de imagem corporal e aspectos de sonolência em treinadores de tênis de Campo Grande. Revista Brasileira de Qualidade de Vida, Curitiba, v. 8, n. 2, p. 175-90, 2016.

LIMA, M. B. N.; ANDRADE, A.; VASCONCELLOS, D. I. C.; FARIA, M. B. Perfil da formação inicial e permanente de treinadores de tênis de alto rendimento do Brasil. Pensar a Prática, Goiânia, v. 17, n. 1, p. 1-18, 2014.

MILISTETD, M.; CIAMPOLINI, V.; MENDES, M. S.; CORTELA, C. C.; NASCIMENTO, J. V. Student-coaches perceptions about their learning activities in the university context. Revista Brasileira de Ciências do Esporte, Brasília, v. 40, n. 3, p. 281-7, 2018a.

MILISTETD, M.; CIAMPOLINI, V.; SALLES, W. N.; RAMOS, V; GALATTI, L. R.; NASCIMENTO, J. V. A. Coaches' development in Brazil: structure of sports organizational programs. Sports Coaching Review, London, v. 1, p. 1-16, 2016.

MILISTETD, M.; GALATTI, L.; COLLET, C.; TOZETTO, A. B.; NASCIMENTO, J. V. Formação de treinadores esportivos: orientações para a organização das práticas pedagógicas nos cursos de bacharelado em educação física. Journal of Physical Education, Maringá, v. 28, n. 1, p. e2849, 2017.

MILISTETD, M.; SALLES, W. N.; BRASIL, V. Z; SAAD, M. A.; NASCIMENTO, J. V. A formação de treinadores esportivos: realidade e perspectivas. In: LEMOS, K. L. M.; GRECO, P. J.; MORALES, J. C. (Orgs.). 5a Congresso Internacional dos Jogos Desportivos. Belo Horizonte: EEFFTO/UFMG, 2015. p. 285-310.

MILISTETD, M.; TRUDEL, P.; MESQUITA, I.; NASCIMENTO, J. V. Coaching and coach education in Brazil. International Sport Coaching Journal, Birmingham, v. 1, n. 3, p. 165-72, 2014

MILISTETD, M.; TRUDEL, P.; RYNNE, S.; MESQUITA, I. M. R.; NASCIMENTO, J. V. The learner-centred status of a Brazilian university coach education program. International Sport Coaching Journal, Birmingham, v. 5, n. 2, p. 105-15, 2018b.

NELSON, L. J.; CUSHION, C. J.; POTRAC, P. Formal, non-formal and informal coach learning: a holistic conceptualization. International Journal of Sports Science and Coaching, Teller Road, v. 1, n. 3, p. 247-59, 2006.

ROCCHI, M.; COUTURE, A. L. Recreational and developmental youth coach learning. Physical Education and Sport Pedagogy, London, v. 23, n. 3, p.
267-79, 2018.

RODRIGUES, H. A. Formação e desenvolvimento profissional do treinador: um estudo sobre os treinadores de basquetebol, suas identidades e saberes. 2014. 233f. Tese (Doutorado em Educação Física) - Universidade Estadual de Campinas, Campinas, 2014.

SANZ, D. R.; FUENTES, J. P.; VILLAR, F. A. La formación del entrenador de tenis. In: TORRES, G.; CARRASCO, L. Investigación en deportes de raqueta: tenis y bádminton. Múrcia: Universidad Católica San Antonio, 2004. p. 34164.

STOSZKOWSKI, J.; COLLINS, D. Sources, topics and use of knowledge by coaches. Journal of Sports Sciences, London, v. 34, n. 9, p. 794-802, 2015.

TENNIS CANADA. Coaching development system. Canadá. 2014. Disponível em: <http://www.tpacanada.com/becoming-acoach/coachingincanada/ coachingdevelopment-system>. Acessado em: 03 de março de 2014.

TOZETTO, A. B.; MILISTETD, M.; SCAGLIA, A. J.; DUARTE, T.; GALATTI, L. Football coaches' development in Brazil: a focus on the content of learning. Motriz, Rio Claro, v. 23, n. 3, p. 1-10, 2017.

TRUDEL, P.; CULVER, D.; WERTHNER, P. Looking at coach development from the coach-learner's perspective: considerations for coach development administrators. In: POTRAC, P.; GILBERT, W.; DENISON, J. (Eds.). Routledge handbook of sports coaching. Abingdon: Routledge, 2013. p. 375-387.

\section{AGRADECIMENTOS}

Os autores agradecem ao Departamento de Capacitação da Confederação Brasileira de Tênis, pelo suporte disponibilização dos dados para este ensaio.

\section{CONFLITO DE INTERESSE}

Os autores do estudo declaram não haver conflito de interesses.

\section{FINANCIAMENTO}

Este estudo não teve apoio financeiro.

\section{ORCID E E-MAIL DOS AUTORES}

Caio Corrêa Cortela (Autor Correspondente) ORCID: 0000-0003-4827-1638.

E-mail: capacitacao@cbtenis.com.br

Cesar Kist

ORCID: 0000-0001-5498-7291.

E-mail: cesar.kist@cbtenis.com.br

Michel Milistetd

ORCID: 0000-0003-3359-6878.

E-mail: michel.milistetd@ufsc.br

Jorge Both

ORCID: 0000-0002-8238-5682.

E-mail: jorgeboth@uel.br

Carlos Adelar Abaide Balbinotti

ORCID: 0000-0002-6358-1848.

E-mail: carlos.balbinotti@ufrgs.br 